\title{
EL DERECHO A VIVIR EL MORIR
}

\author{
Pedro Garín
}

El enunciado de este artículo es traducido por nuestra sociedad como derecho de la persona a morir con dignidad.

Este derecho lo reclama el Congreso Mundial de Enfermería en sus conclusiones, recientemente celebrado en Madrid (El País, 26 de junio de 1993, 25).

Nadie pone en duda, sea creyente o no creyente, que debe respetarse dicho derecho.

Esta constatación social en el enunciado, no la encontramos en su concepción (el sentido de la vida), cuyo enfoque está condicionado a las doctrinas filosóficas y políticas dominantes.

Si vamos a la historia, observaremos la evolución conceptual de este derecho. Desde la «muerte dulce», entendido lo «dulce» como lo más «bello» posible, contrapuesto a lo feo (valores estéticos) en la cultura griega, hasta el presente: «el derecho de la persona a morir con dignidad» (valores éticos), entendido como un derecho de la persona a disponer erga omnes de su propia vida y, por ende, de su muerte (Magno A., Eutanasia. Profili canonistici e civilisti per una soluzione del problema. Ed. Cenaculo Albertino. Bologna (1988), 14 y ss.).

Adentrándome en esta película de la vida real, brotan muchos interrogantes, pues comprobamos que no podemos prescindir de los diversos sujetos actores íntimamente involucrados (el enfermo, que es el protagonista, alrededor del cual gira la historia, el personal sanitario, la familia, la sociedad) y sus respectivos factores concomitantes endógenos y exógenos (v.g., creencias, dolores insoportables, enfermedad incurable, fase terminal, problemas económicos, sociales, etc.).

Este dato (la imposibilidad de prescindir de los sujetos y factores concomitantes) nos conduce a pensar que no debemos permanecer en el terreno de lo abstracto. 
Más, por otra parte, en orden a una respuesta digna del caso concreto, se impone previamente la leal y sincera aceptación de los valores éticos, que tienen la virtualidad de crear actitudes universales, válidas para todas las situaciones particulares (Vidal M., Moral Fundamental I. Madrid (1990), 414 y ss.).

Creemos que esta imposición nace del mismo enunciado, que transciende el campo de lo jurídico y exige internarnos en el mundo de la axiología; es decir, en el mundo de lo ético y religioso.

\section{El derecho del hombre a disponer de su propia vida}

Opinamos que esta tesis: el derecho de la persona in se ipsum, postulado de la ideología liberal, es la que subyace en los movimientos en pro de la legalización de la eutanasia.

Ejemplo confirmatorio de esta opinión lo encontramos en las manifestaciones de D. Ramón Sampedro, tetrapléjico: «cada uno debe hacer con su vida lo que quiera. Creo en el derecho a decidir mi muerte cuando quiera y yo lo quiero ahora» (El País, 10 de julio de 1993, 26).

En virtud de este derecho, en algunos países (Estado de California) se practica el sistema conocido del testamento vital, por el que una persona, en la previsión de encontrarse en un futuro en tales condiciones, suscribe un documento, en el que declara conscientemente que se somete a la práctica de la eutanasia, eximiendo de toda responsabilidad al que lo practica o en que en tales circunstancias se suspenda el tratamiento, cuando no exista esperanza de vida (Lega, Manuale de bioética e deontología médica. Ed. Giuffre. Milano (1991), 280).

Este deseo se ha hecho realidad en Holanda, antes por la vía de los hechos (la admisibilidad práctica) (Eutanasia, Ed. Paulinas (1993), 26), ahora por la vía legal, poniendo como exigencia la petición expresa de muerte por parte del paciente (ABC, 31 de julio (1993), 61): la eutanasia solicitada.

Más aún, en Suecia, al menos por parte de Asuntos Sociales, se tiende a instaurar el derecho de permitir a los médicos interrumpir el mantenimiento artificial de la vida de pacientes irrecuperables o la de recién nacidos con malformaciones irreversibles: la eutanasia impuesta (El País, 29 de mayo, 1991).

En Inglaterra, este permiso se obtuvo por la vía judicial (Sala de la Familiar de la High Court), interrumpiendo la alimentación artificial del joven de 21 años, Tony Bland, que se encontraba en coma (El País, 20 de noviembre, 1992, 30). 
Otros, sin llegar a exigir su legalización, alzan sus voces en pro de la despenalización: no debe sancionarse a aquel que por piedad provoca la muerte del paciente:la eutanasia involuntaria.

Leemos en nuestros medios de información que en el Estado de Michigan se instauró en febrero de este año la ley del suicidio: ayudar a morir a los enfermos (El País, 18 de agosto (1993), 15).

Esta tendencia a la despenalización la vemos plasmada en nuestro proyecto del Código penal, en cuanto se intenta a atemperar notablemente la pena a quien «causara o cooperase activamente con actos necesarios a la muerte de otro, por la petición de éste, en el caso de que la víctima sufriera una enfermedad grave que hubiera conducido necesariamente a su muerte, o que produjera graves padecimientos permanentes y difíciles de soportar» (lib. IV, art. 149, n. ${ }^{\circ} 4$ ).

Estas voces se dejan sentir en el Consejo de Europa, a través de la Comisión de Salud del Parlamento Europeo, que, por el momento, no han sido legalmente aceptadas por el Parlamento (Lega, o.c., 299 y ss.).

El Card. Martini, haciéndose eco de este rechazo, afirma que las leyes no pueden ser «licencias de muerte» (Viaggio nel Vocabolario de l'Etica. Ed. Piemme. Milano (1993), 102).

\section{La eutanasia solicitada}

¿El hombre tiene derecho a disponer de la vida a su arbitrio?

¿La acción más digna de la persona, llegado a esta última etapa de su vida, sometida a dolores insoportables, es el de pedir (exigir) la muerte?

Desde nuestra creencia, nuestra respuesta es negativa, en cuanto partimos que el hombre no es dueño de la vida, sino un administrador sometido a la soberanía de Dios (Haering, Etica médica. Ed. Paoline. Roma (1972), 119).

La vida es un don de Dios, por lo que nadie puede pedir la propia occisión a otros. Dicha petición constituye «el rechazo de la soberanía de Dios y de su designio de amor hacia ellos mismos». Se trata, por lo tanto, de una violación de la ley divina (Instr. de la Doctrina de la Fe, «Donum vitae» (1987), n. os 4 y 5; Declaración de la Doctrina de la Fe, «Iura et bona» de euthanasia (1980), en EV., 7, 355-357).

Dejando, por el momento, nuestras creencias, nos preguntamos: ¿de la lectura de la Constitución española podemos deducir su posible legalidad? ¿Es posible constitucionalmente su despenalización en determinadas circunstancias?

El constitucionalista prof. Alzaga, comentando el artículo 15: «Todos (se refiere a las personas) tienen derecho a la vida y a la integridad física 
y moral», se pregunta si «de la constitucionalización del derecho a la vida se puede colegir la existencia de un derecho al suicidio o debe, antes al contrario, deducirse la obligación del Estado a prohibirlo».

«Lo cierto es que de la redacción de este precepto constitucional el bien que se intenta proteger jurídicamente es el "derecho a la vida", sin que ello afecte a la anómala voluntad de morir» (Const., Esp. de 1978. Ed. Foro. Madrid (1978), 185).

A la luz de este comentario lo que expresamente se deduce es la protección jurídica del derecho a la vida frente a terceros, e, implícitamente, dado el silencio constitucional: «sin que ello afecte a la anómala voluntad de morir» su posible admisión, bien legalizándola, bien despenalizándola, quedando, en última instancia, la decisión legal en manos de la supuesta aprobación por parte de la mayoría social de las Cortes Generales (la ética del consenso).

Creemos que esta ventana abierta contrasta con el actual Código penal, que considera el suicidio como conducta ilícita, y por eso se castiga penalmente la inducción y el auxilio al suicidio (art. 409).

Confesamos, no obstante, que la sentencia del Tribunal Constitucional del 27 de junio de 1990 (caso, la alimentación forzosa a los huelguistas de hambre de los Grapo) refrenda el comentario del prof. Alzaga. «El derecho fundamental a la vida, en cuanto derecho subjetivo - leemos en la sentencia - da a sus titulares la posibilidad de recabar el amparo judicial frente a los ataques de terceros, sin contar para ello con la voluntad de sus titulares.» «Tiene, por consiguiente, el derecho a la vida un contenido de protección positiva que impide configurarlo como un derecho de libertad que incluya el derecho a la propia muerte» (La Ley (T. 1990-4), 18).

La sentencia nos dice que la ley no prohíbe (no existe en nuestro ordenamiento una regulación legal del supuesto) que el sujeto se prive de la vida propia. Esa disposición de su propia muerte constituye una manifestación del «agere licere».

Según parece, el Juzgado de Primera Instancia de Barcelona mantiene el mismo argumento del Tribunal Constitucional (El País, 9 de julio de 1993, 30).

Ahora bien, la eutanasia exige la intervención de un agente externo al paciente, por lo que, a tenor de la sentencia citada, el amparo constitucional para «vencer la resistencia que se oponga a la voluntad de morir» carece de fundamento legal.

Si el legislador accediera a dicha voluntad vulneraría el contenido esencial del derecho garantizado en su artículo $15 \mathrm{CE}$.

Hacemos nuestras las manifestaciones del portavoz de la Asociación Profesional de la Magistratura, Sr. A. Calderón: «La Constitución contempla en su artículo 15 el derecho a la vida. La vida es un valor protegido por 
el Estado y autorizar la petición de este señor (se refiere al Sr. Sampedro) sería un precedente peligrosísimo (el subrayado es nuestro), pues el Estado no está facultado para privar de la vida a ningún ciudadano aún en las circunstancias más precarias» (El País, 18 de julio de 1993, 20).

Comprendemos, en consecuencia, que se afirme el derecho a la vida frente a la limitación de la voluntad a morir.

Aceptando el silencio constitucional al respecto y la inexistencia de una regulación legal del supuesto, se lee en la citada sentencia que el hecho de privarse el sujeto de su propia vida es una manifestación del «agere licere».

¿Es admisible que la disposición de la vida y, consecuentemente, de la muerte, por parte del hombre, quede anclado en la esfera de la moral?

Todos sabemos que el mundo del derecho tiene su existencia en la esfera relacional, por lo que la afirmación de mi derecho es legítima en tanto y en cuanto no lesione el derecho de los demás.

Somos del parecer que si hay algún derecho que implica una inevitable responsabilidad «versus» la humanidad es el derecho que tratamos (Haering, o.c., 28).

Consideramos que el derecho de vivir y el derecho de morir es un derecho que se proyecta en la sociedad y compromete a la misma, por lo que la sociedad y sus instituciones no pueden ni deben permanecer al márgen del ejercicio de este derecho.

El hombre, nos enseña Sto. Tomás, es parte de la comunidad, y, por lo tanto, todo lo que es él pertenece a la sociedad (II-II, q. 64, a. 5). El Vaticano II nos indica que el hombre «no es un elemento anónimo de la ciudad humana» (GS., n. ${ }^{\circ} 14$ ).

La sociedad, en consecuencia, está comprometida frente al pretendido derecho del hombre a la vida. No puede sustraerse al deber de protegerse a sí misma, porque a la larga su permisividad conllevaría a su propia negación existencial. Si la sociedad hiciese dejación de este deber, firmaría su sentencia de muerte.

No cabe, por ello, disociación entre este pretendido interés de la persona y el interés social. Lo que daña a la persona, daña a la sociedad y viceversa, pues toda vida humana es vida coexistente (existencia compartida). Como explica Zubiri «Vivir es vivir con las cosas, con los demás y con nosotros mismos en cuanto vivientes» (El acontecer humano: Grecia y la pervivencia del pasado histórico, filosófico en Nat., Hist., Dios. Madrid (1944), 434).

Por eso Sto. Tomás afirma que el suicidio es una injuria a la comunidad (o.c.) y la Iglesia considera delito la eutanasia (GS. n. ${ }^{\circ} 27$ ) y sostiene que su implantación, además de una violación divina, es un atentado contra la humanidad: la destrucción de la misma sociedad (o.c., en EV., 7, 354-357). 
Su legalización son cesiones a la violencia, ofensas al derecho e injusticias contra la persona y, por ende, contra la sociedad (Catecismo, n. ${ }^{\circ}$ 2.277).

La sociedad se protege a sí misma buscando los cauces, a través de sus instituciones, que hagan realidad la vida personal; es decir, todo lo que el hombre necesita para llevar una vida dignamente humana (GS. n. ${ }^{\circ} 26$ ), pues no debemos olvidar que el principio, sujeto y fin de toda institución social es la persona humana (GS. n. $\left.{ }^{\circ} 25\right)$. El ser humano - formula Kant- ha de ser tratado como fin en sí mismo, nunca como medio.

La realización de esa vida personal la consigue el hombre en sus relaciones reguladas por normas que respeten la dignidad de toda persona y sus derechos inviolables.

La fuerza del derecho está en la bondad de sus leyes, en el bien común que las leyes deben perseguir y conservar (Martini, o.c., 102). Está - dice el mismo Cicerón - en la bondad, en el amor fraterno, como fruto de la recta razón, de la que emerge la ley inmutable, universal, válida para todos los tiempos, la cual manda las acciones rectas y prohíbe las contrarias (De re Publica, 3, 33).

Una ley que legitime o tolere la pretensión de una persona a morir, pierde la razón de su existencia, pues, en realidad, socaba la dignidad de la persona (art. $10 \mathrm{CE}$ ) y anula sus derechos de modo definitivo.

La vida, en su dimensión objetiva, dice el Tribunal Constitucional es «un valor superior del ordenamiento jurídico constitucional» $\mathrm{y}$ «supuesto ontológico sin el que los restantes derechos no tendrían existencia posible» (STC. 53/1985).

\section{La libertad}

¿Impedir el ejercicio de este derecho no es un atentado a la libertad de la persona, constitucionalmente reconocida como derecho de la persona (art. 1, 1 CE) y una violación de lo preceptuado en el artículo 9, 2 CE?

La sentencia citada del Tribunal Constitucional nos indica que el contenido del derecho a la vida no se configura como un derecho de libertad que incluya el derecho a la propia muerte, por lo que desde la perspectiva del bien que se intenta jurídicamente proteger (la vida frente a terceros), la oposición a la voluntad de morir no implica la vulneración del derecho fundamental de la libertad.

Aceptando la parte expositiva y decisiva de la sentencia (se trata de defender el valor de la vida frente a terceros), creemos que el auténtico fundamento humano de la libertad está íntimamente unido al de la responsabilidad ante la naturaleza, que nos hace ver no sólo la repercusión 
social del valor de la vida, sino también su incidencia negativa a nivel personal, pues, como señala el mismo Tribunal, la vida es el supuesto ontológico de la existencia de los restantes derechos, entre ellos, el derecho a la libertad (art. 17, $1 \mathrm{CE}$ ).

Por ello, no entendemos que el pretendido derecho a morir no afecte a bienes constitucionales («Voto particular del Sr. Leguina Villa», o.c., 22-23).

Creemos que el derecho a la vida en su dimensión humana se encuentra indisolublemente unido a la dignidad de la persona, pues es inconcebible una dignidad humana sin la plena existencia física, por lo que ésta tiene el carácter de la inviolabilidad (art. $18 \mathrm{CE}$ ).

En la medida en que la vida quede a merced del sujeto que la posee, la dignidad personal se degrada, haciendo inalcanzables los objetivos de la paz social y de la estabilidad del orden político (art. $10 \mathrm{CE}$ ).

\section{El uso honesto de la libertad}

El Tribunal Constitucional nos dice que el uso de la libertad es para conseguir lo lícito legal, supuesto que este «lícito legal», añadimos por nuestra parte, se asiente en esos valores éticos válidos para todas las situaciones particulares.

Una cultura de la legalidad debe enraizarse en un profundo «ethos» personal y social. Las leyes deben respetarse no sólo por su valor formal o por las sanciones que conllevan su inobservancia (si así sucediera, entraríamos en el puro legalismo), sino también, y, sobre todo, por su valor y significado intrínseco, por su capacidad de representar los ideales y fines de la colectividad (Martini, o.c., 100-102), que no puede ser otros que el desarrollo integral de la persona (legitimidad material).

«La ley, si es ella puramente humana — nos dice Setién- no puede ser el principio fundante del orden ético, ya que ella misma está postulando unos principios metajurídicos de legitimación» («Valores éticos para el actual momento cultural vasco», en el $B O D$, abril, n. $^{\circ} 500$, (1993), 535 y ss.).

Esta exigencia de reclamar tales principios metajurídicos nace del hecho de que «omnis lex humanitus posita intantum habet de ratione legis, inquantum a lege naturae derivatur» (Sto. Tomás, Summ. Theol. I-II, q. 95, a. 2).

Esta transcendencia del derecho como hecho, hace que el derecho, sin perder su carácter existencial, no pueda reducirse jamás a una realidad, por así decirlo, material e inmediata del orden sociológico (legitimidad formal).

Hecha esta observación, es verdad que la libertad, en cuanto estructura de la persona, es ilimitada: el hombre es libre de aceptar o aniquilar la vida. No cabría hablar de libertad si se negara a la persona la posible elección de lo opuesto. 
Mas tan cierto es también que desde dentro de esa libertad nacen unas libertades limitadas en el orden operativo, que brotan del centro de la personalidad: "no todo lo que puede hacerse, se debe hacer». Zubiri nos dirá que la libertad humana es una libertad «encarnada» («El hombre, realidad personal». Revista de Occidente I (1962), 21).

Puede hacerse — ser - si el hombre es conceptuado como objeto de laboratorio (una máquina de relojería), cuyo desguace está al servicio de parciales intereses, ajenos a su propia dignidad. En esta dinámica todo es posible (si Dios no existe todo es posible, lo dijo Dostojevski).

No debe hacerse - deber ser- (a beneficio personal y ajeno), si consideramos que el hombre es el fin de la creación, y entonces no es posible atribuir a la naturaleza, si de verdad queremos respetarla, nuestros particulares intereses, valorados «éticamente» bajo el plisma de la mera subjetividad.

Desde la óptica trascendente (el Dios que nos crea y nos ama), la libertad del hombre está en función de hacer «nuevas todas las cosas» (libertad para). La persona se encuentra implantada en el ser (en la vida) para realizarse. «En el designio de Dios —enseña Pablo VI - todo hombre está llamado a desarrollarse, porque cada vida es una vocación» (Populorum progessio, $\left.\mathrm{n}^{\circ}{ }^{\mathrm{o}} 15\right)$. Esta llamada es obediencia a la naturaleza, pues, la personalidad no nace, se hace.

La presencia de esta llamada a la plena realización de sí mismo, constante y dinámicamente abierta al futuro, exige no encerrarse en circuitos de valores totalmente subjetivos, que nos llevaría a vaciar nuestra libertad de toda su dignidad ( En busca del verdadero rostro del hombre. Carta pastoral de Cuaresma», 1987, en el BOD, marzo (1987), 153 y ss.).

El modo de realizarse el hombre es haciendo el Bien.

El Bien («bonitas entis»), al que el hombre es llamado, es una realidad ontológica previa a toda opción personal, que se impone por sí mismo. Ninguno, por lo tanto, incluida la voz de las mayorías, tiene libertad para denominar bien (el homicidio) o lo que es mal (privación del bien) o viceversa.

El bien o el mal se fundamentan en la ley moral objetiva, descrita por Cicerón como «razón suprema escondida pero real en la naturaleza» (De leg. 1, 6).

En esta ley se revela un orden objetivo (supraindividual) de valores, intrínseco a la persona humana, que vincula en conciencia al hombre - a todo hombre- en su actuación libre y responsable. Este orden de valores, en virtud de su connotación personalista se impone por sí sólo y frente a todos; por lo que no puede ser manipulado por ninguna 
intervención (poder) humana, en cuanto es anterior y superior a dicho poder.

Este orden de valores (el bien, el amor, la justicia, etc.) se concreta, en el espacio y tiempo, en el respeto de los derechos-deberes fundamentales humanos, definibles como «exigencias ínsitas en el ser humano y derivadas del mismo, que se ponen ante la conciencia como obligatorias de ser legalmente reconocidas y tuteladas» (AA. VV., Il diritto nel mistero della Chiesa, I. Univ. Lateranense. Roma (1988), 8 y ss.).

Uno de esos valores es el valor de la vida (la vida en sí) reconocido por el mismo Tribunal Constitucional como «valor superior del ordenamiento jurídico constitucional» $\mathrm{y}$ «supuesto ontológico sin el que los restantes derechos no tendrían existencia posible».

Es un valor que se impone por sí mismo, en virtud de una exigencia objetiva, si en realidad pretendemos una vida auténtica y plenamente humana.

Por ello, no comprendemos que en nombre de la libertad se considere como bien jurídicamente a proteger la solicitud de la eutanasia (El País, 18 de julio, 1993, 20), ni que pueda ser objeto de un compromiso nominal, en que el valor de la vida sea vivido como algo producido por el hombre, transformable y, en cierta manera, relativo.

Entre las libertades que brotan de la libertad está para el creyente la libertad (liberadora) para aceptar el hecho de que la vida natural no tiene derecho en sí misma, sino en Dios. La libertad dada al hombre en la vida natural, la libertad para la muerte, sufre un abuso, (un uso deshonesto) cuando no se la emplea con fe en Dios (Bonhoeffer D., Etica. Ed. Estela. Barcelona (1968), 115-120).

\section{La libertad religiosa}

No negamos que entre los valores éticos de rango universal, consideremos el derecho de la persona a su libertad en lo religioso. Derecho que se consagra en la Constitución (art. 16, 1).

Si bien el fundamento del derecho a la vida y el derecho a la libertad religiosa es el mismo: la dignidad de la persona humana, no debemos olvidar que el derecho a la libertad religiosa no es un derecho ilimitado, como se desprende de su objeto: «inmunidad de coacción que tiene la persona en materia religiosa en lo civil y social frente a toda potestad humana».

El Tribunal Constitucional reconoce que la libertad ideológica no se agota en una dimensión interna del derecho, sino que comprende una dimensión externa del «agere licere». 
Dada esta dimensión externa del «agere licere», ésta queda garantizada constitucionalmente, sin más limitaciones que las necesarias para el mantenimiento del orden público protegido por la ley (art. 16, $1 \mathrm{CE}$ ).

La Declaración conciliar «Dignitatis humanae» nos pone también como límite del derecho a la libertad religiosa el «orden público». Mas, por evitar toda arbitrariedad conceptual del término «orden público», juzgó pertinente señalar el contenido del mismo: «el derecho a tutelar los derechos de los demás, el derecho a promover la honesta paz pública y el derecho a la custodia de la moralidad pública». (n. $\left.{ }^{\circ} 7\right)$.

La defensa de tales derechos (parte fundamental del bien común) es necesaria para la existencia misma de la sociedad.

A tenor de esta clarificación conciliar, creemos que podemos aplicar al caso lo afirmado por los Obispos españoles, referente a la legalización del aborto: «(...) el inviolable respeto a toda vida humana es un principio fundamental que debe ser legalmente salvaguardado. Una sociedad en la que el derecho a la vida no está legítimamente protegido es una sociedad intrínsecamente (el subrayado es nuestro) amenazada. Por ello, aun siendo verdad que el legislador no está obligado siempre a penalizar toda infracción moral, es deber suyo, en razón del bien común la defensa y protección de toda vida humana» (Comisión permanente. Nota 13).

Opinamos que dentro de este contexto cabe interpretar el artículo 31 del Código deontológico médico (31 de marzo de 1993), en el que se establece que el médico respetará la libertad del enfermo, persuadiéndole que deponga su conducta; mas, llegado al caso límite, aplicará previo requerimiento judicial, la imprescindible asistencia médica.

En la guía europea de ética médica y conducta profesional de los médicos (diciembre de 1982), referiéndose al acto suicida, se afirma que la obligación del médico es ayudarle y prestarle asistencia necesaria, sobre todo, cuando el suicida ha perdido completa lucidez. El médico no está obligado a respetar las razones (v.g., las religiosas) del suicida.

En parecidos términos se manifiesta con respecto a los huelguistas del hambre: Cuando aparecen signos de perturbación mental, juristas, moralistas y médicos interrogados retienen que el médico deba socorrer e intervenir inmediatamente (Documenti di deontologia y ética médica. Ed. Pauline. Milano (1985), 71).

Todas estas citas revelan que ese pretendido derecho del hombre a decidir cuando y cómo quiere morir en nombre de una pretendida libertad (incluida la religiosa) sobrepasa su legitimidad frente al derecho cierto de la vida, por lo que en lugar de afirmar un derecho, tenemos que hablar de un abuso de derecho (un uso deshonesto), en cuyo caso el derecho a la libertad pierde su relevancia jurídica (Dabin J., Le droit subjetif. París (1952), 268-304). 


\section{El acto humano}

Al margen de nuestras reflexiones jurídicas, éticas y religiosas, nos detenemos en los elementos configuradores del acto humano.

Consideramos necesario preguntarnos si una persona en tales condiciones penosas goza de conciencia y libertad para tomar tal decisión. ¿Podemos afirmar que existe un acto consciente y libre?

La Declaración de la Doctrina de la Fe nos pone en guardia al decir que las súplicas de los enfermos no deben entenderse como expresiones de una verdadera voluntad de morir (el subrayado es nuestro) (o.c. EV., 7, 357) ¿Por qué?

No debemos olvidar que todo acto humano exige discernimiento ( $\mathrm{va}$ loración) de lo que se va a elegir (autodeterminación).

¿Cabe esta autodeterminación en el titular de este pretendido derecho, cuando se encuentra psíquicamente incapacitado de realizar una valoración de su decisión?

Creemos que este interrogante es válido también en el supuesto del testamento vital, entendido como mandato hecho a una persona para que acabe con la propia vida en caso de estar gravemente enfermo, impedido o con fuertes dolores.

¿Es que el hombre lo que pensó y quiso en un tiempo de bonanza física y mental, no puede cambiar de parecer en el momento del ocaso de sus días? ¿Se puede dictaminar la voluntad del enfermo en esa fase aguda?

¿No experimentamos el vertiginoso y constante cambio mental de nuestra sociedad, de forma que lo que un día fue imposible concebir, hoy lo aceptamos como normal?

¿Tenemos certeza moral que el paciente, llegado a esta última etapa de su vida, mantiene aquella actitud testamentaria de exigir la muerte?

En la citada guía europea de ética médica, refiriéndose al suicida, leemos que no es inconcebible que durante la trama del suicidio, la persona experimente en el último momento un sentimiento de angustia, incluso de remordimiento por su actitud, de forma que en el subconsciente brote el instinto de conservación y el deseo de vivir (Documenti, o.c., 71).

\section{Eutanasia involuntaria}

Un principio de nuestra moral es que el fin (aliviar el dolor) no justifica los medios (el cese directo de la vida).

Uno de los argumentos de los defensores de la eutanasia, quizá de buena fe, es que mantener a un ser humano en tal situación angustiosa, más que un acto de protección es un acto de tortura. 
Opinamos que esta defensa de la eutanasia, por el motivo alegado, carece de base, pues, aparte que sería deseable una matización del término «tortura» (Véase su significado jurídico en el STC, 120/1990 de 27 de junio), los datos de la ciencia médica revelan que, sin necesidad de provocar la muerte, existen en poder de los médicos los apropiados remedios analgésicos que eliminen todos los sufrimientos físicos y psíquicos, aún a sabiendas que su uso prolongado abrevie la vida, cuya licitud, en casos límites, es admitida por la misma Iglesia (EV, 7, 362).

Por ello, consideramos que no se sustenta los motivos «de piedad»o «compasión».

Independientemente de los datos de la ciencia médica, no podemos negar las graves consecuencias que acarrearía una conducta fundamentada sobre criterios (sentimientos) subjetivos, pues, como señala el Comité episcopal para la defensa de la vida, «no habría posibilidad de establecer normas generales de comportamiento y estaríamos en la ley de la selva, donde impera la ley del más fuerte» (Eutanasia, o.c., 54). Recordemos la eutanasia eugenésica de la Alemania nazi (Lega, o.c., 278-279).

La aceptación de la muerte «por piedad» en el fondo, infravalora el cuerpo (el cuerpo como objeto), ignorando que el cuerpo, aún disminuido, es parte constitutiva de la persona, y, como tal, exige respeto (el hombre es también cuerpo) (GS., n. $\left.{ }^{\circ} 14\right)$, o bien, lo hipervalora, como se desprende del interrogante formulado en la editorial del País (11 de julio de 1993, 10): ¿Puede calificarse de vida la de una persona que se siente como una cabeza pegada a un cuerpo que es incapaz de satisfacer la más elemental función humana?

¿Qué sería del hombre - nos preguntamos- si todo se resolviera en el breve ciclo de su vida biológica?

La vida humana no es un resultante de una relación equilibrada entre la mente y el cuerpo. El hombre es un ser «unitario en su dualidad de cuerpo y alma» (GS., n. $\left.{ }^{\circ} 14\right)$. Todo acto del ser humano es al mismo tiempo una actividad psicosomática.

La vida humana nos dice el Comité episcopal para la defensa de la vida, «en su dimensión corporal participa de la dignidad de la persona», razón por la que al hombre no le está permitido despreciar su propia vida corporal, sino que está obligado a considerar su cuerpo como «bueno y digno de honor» (GS., n. $\left.{ }^{\circ} 14\right)$.

El cuerpo, por otra parte, «no se identifica con esta dignidad». La persona humana es cuerpo, pero es también más que cuerpo (Eutanasia, o.c., 98). Por eso, la vida humana no puede reducirse a la corporeidad de su ser. Participa de la luz de la mente divina (GS., n. ${ }^{\circ} 15$ ), capaz de discernir lo bueno de lo malo. 
El recordado prof. Rahner en breves palabras condensa la dignidad del ser humano: «el hombre es persona que consciente y libremente se posee» («Dignidad y libertad del hombre». Escritos teológicos II. Madrid (1962), 256).

Sería degradante considerar al ser humano como un «computer», que por muy sofisticado que sea, sólo puede operar sobre datos suministrados por su programador.

El hombre creado a «imagen de Dios» (GS, n. $\left.{ }^{\circ} 12\right)$ puede asumir responsablemente unas decisiones, «de modo que sepa buscar espontáneamente a su Creador» (GS, n. $\left.{ }^{\circ} 17\right)$. Posee un modo de sentir y de actuar que le pone en contacto a nivel de conciencia con los valores y con la verdad (DH. n. ${ }^{\circ}$ 1).

Se podrá programar el cerebro electrónico para que «diga la oración», pero no podrá jamás vivirla en un actitud de apertura hacia la humanidad. Sólo el hombre puede darse libremente por amor. Y esa donación la realiza en el cuerpo y a través del cuerpo. Como explica Haering, el cuerpo no es un objeto, sino una palabra encarnada, un mensaje y una llamada. El hombre es un espíritu encarnado; es un cuerpo vivo (o.c., 88-92).

\section{Relaciones médico-enfermo y viceversa}

Dentro de esta temática opinamos de «obligado cumplimiento» resaltar las relaciones específicas de estos sujetos que, a nuestro juicio, merecen especial atención.

El recurso a un profesional revela un gesto de confianza, y, si el recurrente es un paciente, este gesto entraña un calado muy particular.

El enfermo se abre al médico, confiando plenamente que éste acierte en el diagnóstico y le dé una solución «de vida» (Código médico, art. 22, 1). Afirmar lo contrario, sería un caso patológico.

Pues bien, si aceptamos como legítima la muerte «por piedad» (a veces la situación penosa que se intenta eliminar afecta al mismo sujeto que practica la eutanasia), la confianza que debe imperar en las relaciones médico-enfermo desvanece al otorgarle al médico el poder de matar.

Leemos en un diario nacional que «los ancianos holandeses temen la eutanasia al ser hospitalizados». Apoyándose en un estudio realizado por la Unión Protestante Cristiana de Ancianos, se dice que el proyecto de ley de despenalización de la eutanasia otorga la facultad de decisión al médico de practicarla, si «el paciente es incapaz de hacerlo: demencia senil, perturbación mental, personas en coma o recién nacidos con malformaciones» (ABC, 31 de julio de 1993). 
Contemplamos, desgraciadamente, lo sucedido en Albano (Italia), al provocar la muerte de un enfermo terminal de cáncer, no por poner fin a sus dolores, sino por razones pecuniarias, previo acuerdo con una agencia funeraria, que se obligaba, como contraprestación, a publicar su defunción $(O R, 30$ junio-1 de julio de 1993, 3).

Creemos que la muerte «por piedad» abre aún más las puertas de la degradación del hombre, convirtiéndose en infrahombre.

Quienes la defienden en aras de la dignidad humana, aparte de arrogarse un juicio de valor, erróneo a nuestro entender, al considerar que la persona en esas condiciones deja de ser sujeto (persona), hace que esa dignidad que proclaman, quede a la valoración arbitraria del más fuerte.

Como prueba de este juicio erróneo, resaltamos el hecho de una joven británica de 19 años en coma profundo, conectada a un sistema de respiración artificial. Se le descubre que está embarazada. Los padres de la joven pidieron a los médicos que la mantuvieran con vida para salvar al feto. El embarazo siguió desarrollándose con normalidad, pero la madre no daba muestras de recuperarse. Merlanie dio a luz, y a los 10 días «para sorpresa general», abrió los ojos. «A la mañana siguiente, la joven es capaz de reconocer a su familia y de mantener conversaciones simples mediante signos» (El País, 28 de junio de 1993, 30).

Terminamos este apartado recordando la afirmación de Juan Pablo II, en su alocución a los miembros de la Academia europea de anestesia (8 de setiembre de 1988): «Ninguno puede ser árbitro de la vida humana, sea médico, sea cualquier persona» (Lega, o.c., nota 28, 295).

\section{Ortotanasia}

De la «recta ratio» emerge para el creyente un conocimiento que Dios es Señor de la vida, que al hombre le es confiada la altísima misión de protegerla, recibida en don y que esta misión ha de cumplir de modo humano (EV, 7, 364-371).

¿Qué entendemos por «modo humano»?

La Declaración de la Doctrina de la Fe nos ilumina al respecto, al decir que no debe maravillar si algunos cristianos desean moderar el uso de los analgésicos para aceptar voluntariamente al menos una parte de sus sufrimientos y asociarse así de modo consciente a los sufrimientos de Cristo crucificado.

No sería, sin embargo, prudente imponer como norma general (el subrayado es nuestro) un comportamiento heróico determinado. Al contrario, la prudencia humana y cristiana sugiere para la mayor parte de los enfermos el uso de las medicinas que sean adecuadas para aliviar y/o su- 
primir el dolor, aunque de ello se deriven como efectos secundarios entorpecimiento o menor lucidez (EV, 7, 360).

En conformidad con lo que precede, deducimos que el enfermo no está obligado a recurrir en todas las circunstancias a toda clase de remedios.

La vida humana no es un valor absoluto al que todos los demás se deban subordinar. Valor absoluto es la dignidad de la persona humana, que está hecha, según nuestras creencias, a imagen y semejanza de Dios.

El enfermo cumple con su misión de buen administrador de su vida, ateniéndose a los medios normales que la medicina le ofrece, aún a sabiendas que la renuncia a otros medios terapéuticos conlleve el acortamiento de su vida.

Esta renuncia puede ser motivada no sólo por su valoración religiosa del dolor, sino también por solidaridad a la familia.

Dice Haering: Figurémonos un padre que ha trabajado duramente y aprovechando toda su vida para asegurar una buena educación para sus hijos, qué terrible sufrimiento tiene que ser para él ver que la breve prolongación de su vida, ya desahuciada, disipe todos los ahorros y recursos necesarios para el futuro de sus hijos (Moral y medicina. Madrid (1972), 130).

El motivo de esta renuncia puede extenderse en beneficio de la colectividad, en cuanto el supuesto uso de tales medios desproporcionados redunde en cargas para los contribuyentes, bien de índole económica (Seguridad Social), bien de índole ocupacional (Centros hospitalarios).

La renuncia a tales medios no equivale al suicidio; significa asumir la muerte inevitable (no la provoca intencionadamente) por hacer el bien por una causa superior (v.g., el martirio, la responsabilidad, la solidaridad, etc.), dejando a la ley de la naturaleza que siga su curso (EV, 7, 353).

\section{Distanasia}

Esta renuncia se impone moralmente en aras de la misma dignidad humana, si el uso del medio desproporcionado tiene como único resultado el de retrasar artificialmente la vida, ocasionando en el enfermo inútiles sufrimientos. Es lo que llamamos obstinación terapéutica (Catecismo, n. $\left.{ }^{\circ} 2.278\right)$.

En el Código deontológico médico se establece: «en el caso de enfermedad incurable y terminal, el médico debe limitarse a aliviar los dolores físicos y morales del paciente, manteniendo en todo lo posible la calidad de una vida que se agota y evitando emprender o continuar acciones terapéuticas sin esperanza inútiles u obstinadas. Asistirá al enfermo hasta el fin, con el respeto que merece la dignidad del hombre» (art. 28, 2). 
En el octubre de 1983, la Asociación médica mundial afirmó: «El médico se abstendrá absolutamente de todo encarnizamiento terapéutico, es decir, de todo tratamiento extraordinario del que nadie puede esperar beneficio alguno en favor del paciente» (Lega, o.c., 287).

La Declaración tantas veces citada de la Doctrina de la Fe considera lícita la suspensión terapéutica, cuando dicho tratamiento tiene como único objetivo la prolongación precaria y penosa de la vida $(\mathrm{EV}, 7$, 371).

Viene a la memoria la carta del Card. Villot, secretario de Estado, dirigida en nombre del Papa (1970) al secretario general de la Federación Internacional de las Asistencias Médicas Católicas: en muchos casos, ¿no sería una tortura inútil (trato inhumano y degradante) imponer la reanimación vegetativa en la última fase de una enfermedad incurable? ¿El deber del médico consiste más bien en hacer lo posible por calmar el dolor en vez de alargar el mayor tiempo posible, con cualquier medio y en cualquier condición, una vida que ya no es del todo humana y que se dirige naturalmente hacia su acabamiento? (en Vidal M., o.c., 282).

El interrogante es ¿a quién corresponde la decisión de esta suspensión terapéutica?

Creemos que la decisión debe partir del sujeto paciente, siempre y cuando, previamente informado, sea capaz de entender y querer.

Esta decisión es signo manifestativo de una voluntad operativa de dejar que la naturaleza se encargue del resultado (EV, 7, 370).

En el caso que el sujeto paciente sea incapaz de esta decisión, ¿corresponde a los familiares o al médico?

Recordamos el caso de Ana Karen encerrada durante muchos años en un pulmón de acero en el hospital de New Jersey (USA). Los padres obtuvieron la orden de suspensión por la vía judicial.

El cardiólogo Barnard en el Congreso internacional celebrado en Niza, año 1984, mantuvo la tesis que sólo a los médicos («bonus vir sanandi peritus») corresponde esta decisión, dado que sólo ellos poseen los conocimientos para enjuiciar la desproporción del resultado con las técnicas terapéuticas puestas en acto (Lega, o.c., 295).

La Declaración de la Doctrina de la Fe resalta también la figura del médico, quien mejor puede juzgar la desproporción del resultado que se prevee, y si la terapia en uso impone al paciente mayores dolencias que beneficios (EV, 7, 369).

Ahora bien, la suspensión del tratamiento no implica la ausencia de asistencia moral y de la terapia razonablemente útil por mantener todo lo posible la calidad de una vida humana que se agota (Código deontológico, o.c. art. 28,2$)$.

¿Qué entendemos por calidad de una vida humana? 
Creemos que el término «calidad» encierra cierta ambigüedad, pues, si entendemos «calidad» como sinónimo de «salud» como bien absoluto, abrimos la posibilidad de colocar la frontera del derecho a la vida con arreglo a controles de calidad cada vez más exigentes, según el grado de egoísmo que impere en la sociedad (Eutanasia, o.c., 56).

Opinamos que el vocablo «calidad» en la terminología médica debe leerse en clave personalista: el vivir (que abarca mucho más que el mero vivir biológico) es preferible a no vivir. Un vivir en el que se haga factible la espiritualización del elemento corpóreo del hombre y la personalización encarnada del componente espiritual (Haering, Etica médica, o.c., 254). Un vivir entendido y valorado desde la alteridad (Vidal M., o.c. II, 177).

La confirmación y extinción de esa calidad corresponde al «bonus vir sanandi peritus», en cuanto es él quien posee a ciencia y conciencia las «armas del arte» (Pío XII, Alocución circa quaestionem de reanimatione, 24 de noviembre de 1957 (AAS, 49 (1957), 1027-1033).

\section{EI derecho de morir humanamente}

Hoy hablamos de una ética civil de los derechos humanos. Una ética que recoja como referentes sustanciales los valores proclamados en la declaración de diciembre de 1948 por parte de las Naciones Unidas. Estos valores se centran en un contenido esencial: la dignidad de la persona.

En pro de esa dignidad se argumenta que el hombre en ese estado de postración angustiosa, sea originada por los sufrimientos insoportables, sea por su enfermedad incurable, sea por su estado comatoso, sea por su situación terminal, deja de ser persona humana.

A lo largo de nuestras reflexiones, hemos intentado plasmar que la dignidad humana tiene valor por ella misma; posee una inviolabilidad axiológica de carácter apriorístico; que en virtud de esa dignidad, la vida humana participa de esa inviolabilidad y que no pierde valor ético por situarse en condiciones de aparente «disminución» física y/o mental; que la vida humana es la base fundamental de los derechos socio-políticos de la persona, por lo que la posible legalización y/o despenalización de la eutanasia conllevaría a consecuencias nefastas para el hombre y, por ende, para la misma sociedad.

Es cierto que el hombre tiene derecho a morir humanamente. Es un derecho que dimana de su propia dignidad «erga omnes», que se encuadra dentro de los derechos de la persona o de la personalidad.

El derecho a esta dignidad se respeta, no con la provocación directa de la muerte, sino creando el clima de serenidad y solidaridad que demanda el enfermo en esos momentos de angustia y ansiedad, haciendo 
posible que el hombre libre y conscientemente acepte su condición humana y pueda a un tiempo valorarla ética y religiosamente.

Uno de los valores de la ética que pregonamos es el de la solidaridad.

La solidaridad no es cuestión de comprensión, sino de justicia, y antes que todo, un imperativo ético.

Una solidaridad abierta, no selectiva, que es lo opuesto a la fraternidad, donde cada miembro de la familia humana debe sentirse comprometido y responsable, máxime ante el necesitado (Etchegaray R., «Il rispetto integrale dei diritti della persona come fondamento di un nuono concetto di sviluppo», en el $O R, 22.5 .93,5$ ).

Solidaridad que, en el caso concreto, se traduce en la prestación al enfermo de los medios que le liberen de la angustia y, llegado el caso, de morir con tranquilidad.

La respuesta efectiva a la demanda del enfermo a morir en paz revela el respeto del derecho a la dignidad de la persona.

Esta paz se concreta en cuidar y aliviar cuando ya no es posible curar. Es lo que llamamos la «medicina paliativa» (Catecismo, n. ${ }^{\circ} 2.279$ ) a realizarla bien en los centros hospitalarios, bien en la asistencia domiciliaria (XVII Jornadas Nacionales de Pastoral de la Salud. Comunicado final).

«Asistir paliativamente a un paciente - dice Wilson Astudillo- implica proporcionarle una atención eficaz de sus síntomas molestos, problemas psicológicos y espirituales, a la vez que se da soporte emocional a los familiares y a todo aquello que afecte al enfermo y a su entorno». (¿Para qué sirven los cuidados paliativos?, en el Diario Vasco, 17 de junio de 1993, 26).

Esta medicina paliativa se plasma en la parábola evangélica del buen Samaritano: dondequiera exista un enfermo, el hombre está llamado a acogerle y curarle (aliviarle), incluso, a expensas suyas. «Se puede afirmar - dice Juan Pablo II- que (el hombre en este "compartir" los dolores de sus semejantes) se da a sí mismo, su propio "yo", abriendo ese "yo" al otro» (Carta Apost. «Salvifici Doloris» de Juan Pablo II sobre el sentido cristiano del sufrimiento, 11 de febrero de 1984, parte VII, n. ${ }^{\text {os }}$ 28-30). El modo de humanizarnos es saliendo de nosotros mismos, en cuanto encontramos fuera la fuente que nos humaniza.

Consideramos que no se trata de un privilegio, sino de un derecho del enfermo (Declaración de los derechos del paciente, artículos 1; 7; 10; Asociación Norteamericana de Hospitales, 6 de febrero de 1973; Carta de derechos y deberes del paciente, artículos 1; 16 (Instituto Nacional de la Salud. España. 1984), por lo que debe ser protegido a tenor de los artículos $15 ; 18,1 ; 24,1 ; 53,1 \mathrm{CE}$. 
Recordamos lo dicho por el Tribunal Constitucional en su sentencia de 8 de abril de 1981: «Se rebasa o se desconoce el contenido esencial (de un derecho fundamental) cuando el derecho queda sometido a limitaciones que lo hacen impracticable, lo dificultan más allá de lo razonable o lo despojan de la necesaria protección» (en $A A$. $V V$., «La ley del aborto». Univ. Deusto (1985), 33).

En lugar de la solidaridad, ¿en los defensores de la eutanasia no prevalece el criterio de la «utilidad»y su derivado «la eficacia»?

¿Si nos atenemos al criterio del utilitarismo (llámese individualismo) no estamos construyendo una sociedad en la que los valores de comunión y de participación desaparecen de acuerdo con una visión puramente mercantil de las relaciones personales y comunitarias? En realidad, como nos recuerda el Papa en Denver, nuestra civilización contemporánea considera «lo bueno» sinónimo de «lo útil» $(O R, 17-18$ agosto 93,7$)$.

Dentro de este contexto, ¿en lugar de defender la dignidad humana, en realidad no estamos socavándola, hasta el punto que el hombre sienta hastío de su vida? ¿Para qué sirve mi vida?

Sin apenas darnos cuenta, estamos construyendo la «cultura de la muerte».

La paradoja de nuestra historia es que una sociedad que alardea ser defensora de los derechos humanos, se sumerge cada vez más en un hedonismo (la vida es digna de vivirla, siempre y cuando no exista espacio al dolor) y en un relativismo, en el que la valoración de la vida se mida a tenor de mis propios intereses.

En razón de ello, se pide a las instituciones que legalice una «ética» que vele por nuestros particulares intereses y, a ser posible, elimine los elementos destructivos del «bienestar» (consumista).

\section{El creyente ante el dolor y la muerte}

Esta paz que demanda el enfermo, para nosotros, los creyentes, adquiere una nueva dimensión.

Esta dimensión, por una parte, nace del principio de que el hombre tiene el deber de ser un buen administrador del don recibido del Creador (el hombre no es dueño de la vida) y, por otra, de la valoración del dolor, dato objetivo de la condición humana, dentro del misterio Pascual.

Por el Crucificado, hecho símbolo de la Buena noticia del amor de Dios al hombre, el hombre ha sido liberado de la opresión del dolor físico y moral: dondequiera exista un enfermo, éste es llamado, pública o secretamente, a unirse a la Cruz del Salvador, colaborando al designio redentor de Dios. 
Esta llamada impulsa al doliente a no sentirse aniquilado. La cruz para el hombre contemporáneo más onerosa consiste en la dificultad e incapacidad de percibir el valor humano y cristiano del dolor; podríamos decir, aunque parezca una paradoja, que la «cruz» más gravosa es la de no reconocer la Cruz ( «Nel segno della croce e dell evangelizacione», en $O R, 4.793)$.

El enfermo debe sentirse gozoso de ser parte activa de la redención del mundo, al transformar el dolor en amor al hombre.

Esta es la raíz de la liberación cristiana: que el dolor se abra en actitud reverencial y amorosa a Dios, que le ha concedido estar unido a la Cruz de Cristo, camino de resurrección para la resurrección de todos (Montanari F., «Il dolore suprema forma di amore e di participazione alla Redenzione del mondo», en $O R, 17.7 .92,4)$.

Con su fe en Cristo Redentor, el creyente manifiesta un firme «sí» a la vida, sin que haya lugar a considerar el dolor y la muerte como enemigos de la verdadera vida. «Deseo partir y estar con Cristo, lo cual, ciertamente, es con mucho lo mejor» (Phil. 1, 23).

El creyente evangeliza motivando la esperanza de querer ser seres vivos con Cristo. «No la paz de la muerte, no la paz de la mera resignación pasiva, sino la paz de la esperanza, como signo de la victoria de Cristo sobre la muerte» (Juan Pablo II, «Gesu Cristo ieri, oggi e sempre in America Latina», en $O R, 23.10 .92,6$ ).

Movidos desde la fe comprendemos el valor de la vida y de la muerte. Vemos que la vida tiene sentido en tanto y en cuanto se abre en pro del hombre (vida humana es vivir para el otro), cuya apertura es una alabanza a Dios, donante de la vida.

Este objetivo (la apertura al hombre) tiene su plasmación en el dolor físico, especialmente en los últimos momentos de la vida, donde el dolor asume un significado particular en el plano salvífico de Dios.

De hecho el dolor, como lo hemos manifestado, es un participar de la pasión de Cristo y un unirse al sacrificio Redentor, quien ofreció su vida en actitud reverencial a la voluntad del Padre (Mat. 27, 34). En esta actitud reverencial es donde, en realidad, revelamos nuestra auténtica personalidad.

Recordemos una vez más al prof. Haering: el hombre que se preocupa sólo de mantener su vida física pierde su verdadero yo, es decir, pierde el sentido de lo que es vivir, así como se desvincula de la participación del amor vivificante de Dios (o.c., 117).

Vida humana quiere decir dignidad y solidaridad. La dignidad de los hijos de Dios y la solidaridad de querernos como hermanos.

Este es el humanismo del Evangelio, que Cristo ha hecho factible. 